\title{
ESTRATÉGIAS PARA O DESENVOLVIMENTO DO USO PÚBLICO DAS APAS DOS MORROS DA BABILÔNIA E SÃO JOÃO, DO LEME E URUBU E PARQUE ESTADUAL DA CHACRINHA, RJ
}

\author{
Ingrid Almeida de Barros Pena ${ }^{1}$ \\ Celso Junius Ferreira Santos ${ }^{2}$ \\ Laura Sinay ${ }^{3}$
}

\section{Resumo}

Este trabalho apresenta os principais resultados de um estudo técnico executado pela Universidade Federal do Estado do Rio de Janeiro (UNIRIO) com o objetivo desenvolver uma proposta estratégica para o uso público de três Unidades de Conservação (UCs) de baixa visitação e alto potencial turístico na zona sul da cidade do Rio de Janeiro. Espera-se, assim, apoiar a implantação do Parque Natural Municipal Paisagem Carioca e chamar atenção para a importância das parcerias entre a gestão de UCs e as Universidades.

Palavras chave: Áreas de Proteção Ambiental; uso público; gestão participativa

\section{Abstract}

This paper presents the main results of a study performed by the Federal University of Rio de Janeiro Estate (UNIRIO) with the objective to develop a strategic proposal for the public use of three protected with poor attendance and high tourism potential in Rio de Janeiro city. It is expected, therefore, support the implementation of the Parque Municipal da Paisagem Carioca and call attention to the importance of partnerships between the protected area's management and the Universities.

Keywords: Environmental Protected Areas; public use; participatory management.

\section{Introdução}

Determinadas áreas naturais de proteção ambiental evidenciam-se como locais de alta visitação, corroborando com a necessidade da ampliação de práticas sustentáveis através da atividade turística. No Brasil, a maioria delas é denominada como Unidade de Conservação da Natureza (UC) tendo como suporte legal, principalmente, a Lei $\mathrm{N}^{\circ} 9.985$, que instituiu o Sistema Nacional de Unidades de Conservação da Natureza (SNUC). Essas áreas têm como

\footnotetext{
1 Mestranda em Desenvolvimento Territorial e Políticas Públicas pela Universidade Federal Rural do Rio de Janeiro (UFRRJ), Especialista em Gestão Ambiental pelo Instituto Brasil PNUMA e Universidade Federal do Rio de Janeiro (UFRJ) e Turismóloga pela Universidade Federal do Estado do Rio de Janeiro (UNIRIO). Email: ingrid.pena@gmail.com.

${ }^{2}$ Gestor das APAs dos Morros da Babilônia e São João e Morros do Leme e Urubu, Secretário Executivo do Mosaico Carioca, Engenheiro Florestal e Mestre em Solos pela Universidade Federal Rural do Rio de Janeiro (UFRRJ). E-mail: cjunius@gmail.com

${ }^{3}$ Professora Adjunta da Escola de Turismologia da UNIRIO, PhD em Manejo de Sistemas Naturais e turísticos pela Universidade de Queensland (Austrália), Pós - doutorado em Geografia pela UFRJ, mestrado em Psicosociologia de Comunidades e Ecologia Social (UFRJ) e Turismóloga pela Faculdades Integradas Hélio Alonso (FACHA). E-mail: laurasinay@gmail.com
} 
modelo dominante os Parques, sendo atribuídos a eles diversificados usos como a prática de atividades esportivas, recreação, turismo, desenvolvimento de pesquisas e projetos de educação ambiental. Considerando a necessidade de conservação de áreas naturais, e a aproximação entre a sociedade e a natureza, conclui-se que o uso conferido aos Parques e às demais UCs é um dos fatores que os torna importantes.

O SNUC possui uma ferramenta de planejamento e gestão que visa planejar e orientar o uso das UCs, que é o Plano de Manejo (PM):

[...] um documento técnico mediante o qual, com fundamento nos objetivos gerais de uma Unidade de Conservação, se estabelece o seu zoneamento e as normas que devem presidir o uso da área e o manejo dos recursos naturais, inclusive a implantação das estruturas físicas necessárias à gestão da unidade (BRASIL, 2000, p.2).

Segundo Leuzinger (2010), para garantir maior eficiência na administração e manejo das áreas naturais protegidas e minimizar os possíveis danos associados à visitação, foi criado o Plano de Uso Público (PUP), um dos documentos componentes do PM. O PUP define as formas sustentáveis de utilização das UCs para conservar seus atributos naturais e históricos, através da análise da infraestrutura, estudo da demanda e otimização de atividades, proporcionando ao usuário a oportunidade de interagir, da melhor forma possível, com a natureza. Apesar da inquestionável necessidade dos PM's e PUP's para o adequado funcionamento das UCs, nem todas as unidades possuem seus documentos técnicos o que gera, atualmente, uma grande preocupação no que concerne ao seu estado de conservação.

No contexto carioca, a preocupação cresce à medida que aumenta a exposição e a demanda turística do Rio de Janeiro. Revela-se a urgência de instrumentos para minimizar os impactos negativos de uso público e maximizar os positivos, destacando-se o planejamento e a gestão.

Por conta do aumento do fluxo turístico no Rio de Janeiro e com a previsão da Secretária de Estado do Ambiente (SEA) e do Instituto Estadual do Ambiente (INEA) de que o número de visitantes em UCs triplique no estado entre 2012 e 2014, pois o Brasil sediará a Copa do Mundo, o mapa das UCs do Rio está sendo redesenhado (RIO DE JANEIRO, $2011)^{4}$. O primeiro passo dessa empreitada foi a constituição legal, técnica e social do Mosaico Carioca através da Portaria N. ${ }^{\circ} 245$ de 11/07/2011, do Ministério do Meio Ambiente (MMA). Este instrumento permite, através do diálogo, articular interesses da sociedade civil e dos gestores das UCs envolvidas. Por meio de ações integradas entre as áreas protegidas envolvidas, o Mosaico Carioca realizou inúmeros estudos técnicos e atividades, desde a sua criação.

Nesta conjuntura, no início do ano de 2012, a Secretaria Municipal de Meio Ambiente (SMAC), representada pelos gestores das Áreas de Proteção Ambiental (APA) dos Morros da Babilônia e do São João, do Leme e do Urubu, e do Parque Estadual da Chacrinha (PEC),

4 Parques da Copa 2014 - Parques Estaduais do Rio de Janeiro. Disponível em: < http://www.rj.gov.br/c/document library/get file?uuid=ba285919-5b5a-4de1-ba8f-

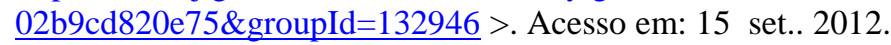


solicitou o desenvolvimento de uma estratégia de otimização do uso público dessas UCs através de uma equipe técnica da Universidade Federal do Estado do Rio de Janeiro (UNIRIO) ${ }^{5}$. As UCs estão localizadas nos bairros de Copacabana, Leme, Urca e Botafogo, conforme indicado na Figura 01. Apesar de incorporar as ilhas do Anel e da Cotunduba, o projeto ficou restrito à porção continental por conta de limitações de tempo e recursos econômicos. Dessa forma, mais estudos ainda serão necessários para analisar o uso público nas ilhas.

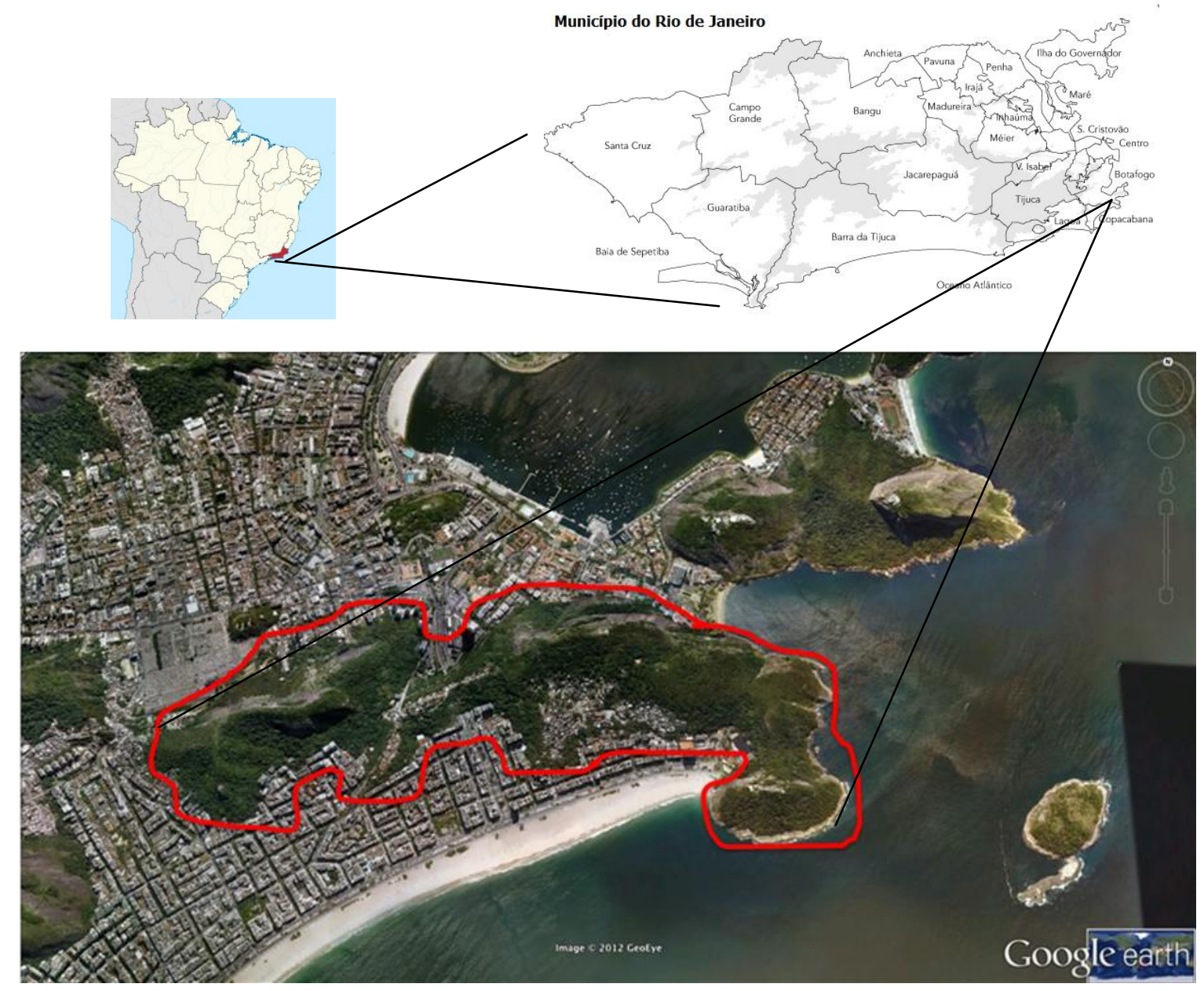

Figura 01. Localização em imagem de satélite (sem escala) da área demarcada das UCs ${ }^{6}$

\footnotetext{
${ }^{5}$ Em 2010 foi criado através da UNIRIO o Projeto Parques, que tem como objetivo contribuir com a gestão sustentável das áreas naturais brasileiras. O projeto inclui atividades de ensino, pesquisa e extensão, pelas quais os alunos e os professores da UNIRIO vêm trabalhando em parceria com gestores de UCs prestando apoio na elaboração de planos estratégicos para a organização e gestão do uso público, desenvolvendo pesquisas científicas a respeito dos impactos das atividades de lazer em áreas verdes e promovendo debates a cerca dos obstáculos e possibilidades de gestão dessas unidades. O estudo em questão teve como orientadora a Prof. Dra. Laura Sinay, como supervisoras Gabriella Brancaccio e Ingrid Pena, e equipe formada por alunos do $7^{\circ}$ Período do Curso de Turismo da UNIRIO.
}

${ }^{6}$ Imagem Google Earth. 
Os objetivos do estudo foram:

1) identificar o perfil dos usuários dessas UCs;

2) avaliar a possibilidade de união das três áreas; e

3) elaborar uma proposta estratégica para o desenvolvimento de seu uso público.

\section{Material e métodos}

A metodologia aplicada no estudo em questão utilizou como base a estrutura dos Sistemas de Gestão de Uso Público, conforme descrito em Sinay (2012) e Fogliatti et al. (2008), adaptando-a às especificidades locais. O projeto teve duração de cinco meses (entre março e agosto de 2012) e contou com sete etapas:

Etapa 1: Em 14 de março de 2012: III Fórum de Planejamento Turístico: Parque Estadual do Chacrinha (PEC) e as Áreas de Proteção Ambiental (APAs) dos Morros da Babilônia e São João, e do Leme e Urubu. Nesse evento, os gestores e os conselheiros dessas unidades, incluindo representantes da ONG Florescer, do Shopping Rio Sul, da Secretaria Municipal do Meio Ambiente (SMAC), da Cooperativa da Babilônia (CoopBab) e da Riotur, palestraram sobre os desafios e as oportunidades de gestão, deram diretrizes para a elaboração do plano de uso público. Definiram como objetivo orientador a fomentação da atividade turística nessas unidades.

Etapa 2: Entre Março e Abril de 2012, a equipe (alunos, professoras, gestores, ONGs, associações) percorreu e mapeou todas as trilhas, verificou as estruturas turísticas, fez registros fotográficos e entrevistou atores sociais (incluindo conselheiros e visitantes) envolvidos no uso e gestão dessas UCs.

Etapa 3: Fontes secundárias, como o Plano de Manejo do PEC e outros documentos de gestão de uso público, foram pesquisadas em busca de informações sobre aspectos da história, biologia, legislação e usos da área.

Etapa 4: com essas informações foi elaborado um diagnóstico da situação, descrevendo aspectos do território, legais, de uso público, de passivo ambiental e de anseios futuros.

Etapa 5: Com base no diagnóstico, foram pensadas cinco estratégias de gestão e avaliados os prós e contras de cada um, fazendo uma análise de cenários. As estratégias de gestão analisadas foram: 1) sem intervenção estratégica, 2) junção das três UCs, 3) as três unidades permanecem separadas, mas sendo geridas por um plano para o Uso Público, 4) união somente das APA's e 5) restrição do uso público.

Etapa 6: Foi desenvolvida a $1^{\text {a }}$ versão de um sistema de gestão de uso público (ver SINAY 2012 e FOGLIATTI et al. 2008).

Etapa 7: No dia 15 de Agosto de 2012, no IV Fórum de Planejamento Turístico, a equipe apresentou a proposta elaborada aos conselheiros mais atuantes dessas unidades, que a aprovaram. 


\section{Resultados}

A variedade de atrativos nessas unidades - que inclui área de recreação infantil (parquinho), vias de escaladas, trilhas curtas e longas, sítios arqueológicos e pontos de apreciação da paisagem - atrai um público bastante diversificado. As Tabelas I, II, e III apresentam de maneira sintetizada as relações entre perfis de usuários e atividades realizadas nas UCs.

Tabela I. Atividades e usuários no PEC

\begin{tabular}{|c|c|c|c|c|c|c|c|}
\hline Atividades de lazer & 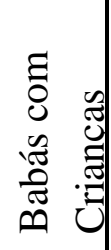 & 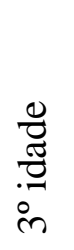 & 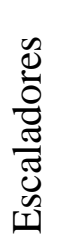 & 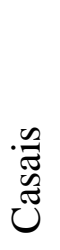 & 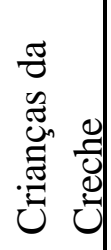 & 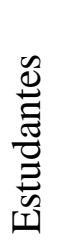 & 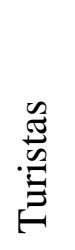 \\
\hline Parquinho, localizado no Playground do PEC & $\mathrm{x}$ & & & & $\mathrm{x}$ & & \\
\hline Circuito para Caminhadas & $\mathrm{x}$ & $\mathrm{x}$ & & $\mathrm{x}$ & & $\mathrm{X}$ & $\mathrm{X}$ \\
\hline Trilhas & & & $\mathrm{X}$ & & & $\mathrm{x}$ & $\mathrm{x}$ \\
\hline Vias de escaladas & & & $\mathrm{x}$ & & & & \\
\hline Campo de Futebol & & & & & & $\mathrm{x}$ & \\
\hline Espaço para festas e atividades & $\mathrm{x}$ & & & & & & \\
\hline Museu & & & & & & & $\mathrm{X}$ \\
\hline
\end{tabular}

Tabela II. Atividades e usuários nos Morros São João, Leme e Urubu

\begin{tabular}{|c|c|c|c|}
\hline Perfil dos visitantes & $\begin{array}{l}\tilde{0} \\
\stackrel{0}{0} \\
\stackrel{0}{n}\end{array}$ & 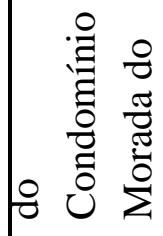 & 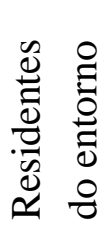 \\
\hline Educação Ambiental & $\mathrm{x}$ & $\mathrm{X}$ & \\
\hline Apreciação da Paisagem & $\mathrm{x}$ & $\mathrm{x}$ & $\mathrm{x}$ \\
\hline Contato com a Natureza & $\mathrm{x}$ & $\mathrm{x}$ & $\mathrm{x}$ \\
\hline Caminhadas em Grupos & $\mathrm{x}$ & $\mathrm{x}$ & $\mathrm{x}$ \\
\hline
\end{tabular}


Tabela III. Atividades e usuários no Morro da Babilônia

\begin{tabular}{|c|c|c|}
\hline Atividades de lazer & 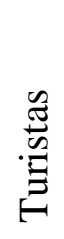 & 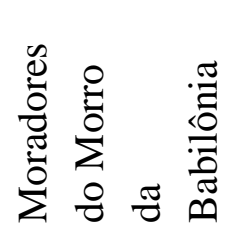 \\
\hline Caminhadas nas trilhas & $\mathrm{x}$ & $\mathrm{x}$ \\
\hline Pesca & & $\mathrm{x}$ \\
\hline Orações & & $\mathrm{x}$ \\
\hline Uso de Drogas & & $\mathrm{x}$ \\
\hline Conhecer os hábitos dos moradores do Morro & $\mathrm{x}$ & \\
\hline Educação ambiental & & $\mathrm{x}$ \\
\hline Apreciar as paisagens & $\mathrm{x}$ & $\mathrm{x}$ \\
\hline
\end{tabular}

\section{Análise de cenários}

As APAs dos Morros São João, Babilônia, Leme e Urubu e o PEC têm uma história interessante começando com a supressão vegetal decorrente da ocupação irregular do solo por pessoas de baixo poder aquisitivo nas décadas de 60 e 70, do século XX. Posteriormente, ocorreu a remoção forçada dessas comunidades e a implantação de um poder paralelo no controle dos morros cariocas. Paralelamente, houve o reflorestamento total dos morros com apoio da comunidade e de forma participativa. Mais adiante, as ações do Estado através da implantação das Unidades de Polícia Pacificadora (UPPs) promoveram a retomada do poder. Atualmente, busca-se consolidar o turismo, mas sem uma estrutura adequada de uso público. Entretanto, um dos aspectos mais importantes é a organização social existente, elemento fundamental para promoção da sustentabilidade do turismo.

As possibilidades para o futuro dessas UCs são muitas e vão depender em grande parte das decisões de manejo adotadas no presente. Para otimizar essas decisões e ampliar as possibilidades de sucesso, foram avaliadas cinco estratégias de gestão sob quatro aspectos, descritos a seguir. Levando em consideração as consequências de cada uma dessas estratégias, optou-se pelo segundo cenário, ou seja, aquele que propõe a união das três unidades num Parque. As razões para a defesa dessa proposta são:

i) a possibilidade de retomada do território pela população local e pelo turismo: intensificando o uso dessas áreas, haveria maior movimentação econômica nas 
comunidades, valorização da área, e diminuiria o uso das áreas como território do narcotráfico. Esses fatores deixariam os moradores satisfeitos quanto à criação de um Parque. Nesse caso, seria importante que eles se sentissem integrados ao desenvolvimento da área, como responsáveis e contribuintes para sua conservação, uma vez que entenderiam que o impacto ambiental prejudicaria a visitação da unidade;

ii) a geração de renda para a comunidade do entorno: mais usuários significaria maior necessidade de ofertas de serviços e produtos, cabendo à comunidade perceber essa demanda e criar oportunidades de emprego e renda;

iii) a visibilidade Turística - Marketing: tornaria a área mais valorizada quando denominada Parque, que carrega uma maior atratividade turística; e

iv) a maior facilidade de gestão: a unificação da gestão tornaria mais fácil gerir as áreas, pois os projetos seriam pensados para um só espaço geográfico, além de facilitar a obtenção de recursos, já que é mais fácil obter verbas para um Parque - mesmo que pequeno - de alta visibilidade na zona sul do Rio de Janeiro, do que para pequenas UCs, que não possuem o merecido destaque e valorização.

\section{Sistema de Gestão do Uso Público}

A proposta para a criação desse Parque foi descrita num sistema de gestão de uso público que inclui fundamentos éticos e morais norteadores. Essa proposta é resumida a seguir:

$\checkmark$ formulação de um Decreto para a junção das três unidades formando um único Parque;

$\checkmark$ definição dos acessos à unidade, seu horário de funcionamento, sinalização a ser implantada;

$\checkmark$ definição das atividades a serem estimuladas e o perfil dos visitantes;

$\checkmark$ definição da estrutura de apoio ao uso público necessária;

$\checkmark$ melhorias necessárias nas trilhas;

$\checkmark$ montagem de projetos sociais e de educação ambiental;

$\checkmark$ estabelecimento do trade turístico;

$\checkmark$ montagem de um plano de contingência para acidentes;

$\checkmark$ avaliação de possíveis impactos decorrentes da implantação da proposta;

$\checkmark$ definição de indicadores e mecanismos associados de monitoramento; e

$\checkmark$ elaboração de propostas para que o uso público seja cada vez mais eficiente.

\section{Consulta pública}

As propostas foram apresentadas à comunidade em reunião do Conselho Gestor das APA do Leme, Babilônia e S. João e serviram como base para a campanha para criação do Parque Natural Municipal Paisagem Carioca. Atualmente, em maio de 2013, a criação do 
Parque conta com a anuência da SEA e da SMAC. Uma comissão de moradores solicitou audiência com o prefeito, apresentando a criação do Parque como uma reivindicação.

\section{Conclusões}

O estudo feito pela equipe da UNIRIO cujos pontos principais foram apresentados neste artigo serviu de base para dar início ao processo para a criação de um novo Parque na zona sul da cidade do Rio de Janeiro, atualmente nomeado de Parque Natural da Paisagem Carioca, propondo-se que sua gestão seja municipal. Ainda que a falta de recursos financeiros e humanos limite o ótimo aproveitamento da área pelos usuários, inúmeros outros estudos são feitos na área - de modo voluntário - por pesquisadores, universitários e outros parceiros.

Crê-se oportuno destacar neste contexto, a relevância da integração entre as universidades e as UCs. O meio acadêmico tem nas UCs importantes laboratórios para produção de conhecimento científico ${ }^{7}$ e, também, para o desenvolvimento (em todas as suas dimensões) de ações extensionistas que proporcionam dinamização das próprias pesquisas universitárias. As contribuições mútuas devem acontecer, portanto, de modo cada vez mais coordenado e integrado.

\section{Agradecimentos}

Os autores agradecem aos reflorestadores da CoopBab pela companhia e trabalho dedicados à equipe nas visitas de campo e pelas entrevistas concedidas com muita paciência. Agradecemos também a toda equipe de alunos que contribuíram para a realização do estudo.

\section{Referências bibliográficas}

BRASIL. Ministério do Meio Ambiente. Reconhece o Mosaico Carioca. Portaria n. 245, de 11 de julho de 2011. Disponível em:<

http://www.mma.gov.br/estruturas/240/_arquivos/portaria_mosaico_carioca_240.pdf $>$. Acesso em: 01 maio 2012.

DNA AVENTURA ECOTURISMO. Classificação de percurso de caminhadas. Disponível em: < http://www.dnaventura.com.br/grade_caminhadas.html >. Acesso em: 29 maio 2012.

FOGLIATTI, M. C.; CAMPOS, V. B. G.; FERRO, M. A. C.; SINAY, L., CRUZ, I. Sistemas de Gestão Ambiental Para Empresas. Rio de Janeiro: Editora Interciencia ,2008. v. 1, 122 p.

\section{LEUZINGER, M. D. Uso Público em Unidades de Conservação.Congresso de Direito} Ambiental da PUC-RIO, 1., 2010, Rio de Janeiro. Disponível em: < http://www.nima.pucrio.br/aprodab/artigos/uso_publico_em_unidades_de_conservacao_marcia_leuzinger.pdf $>$. Acesso em: 23 out. 2012.

\footnotetext{
${ }^{7}$ Segundo Medeiros (2011), sobretudo em áreas típicas das ciências naturais no Brasil, como a zoologia, a botânica e a ecologia, se beneficiaram largamente da existência de UC.
} 
MEDEIROS, R. Unidades de Conservação e pesquisa científica: a contribuição da Academia para o processo de ampliação e consolidação do Sistema Nacional de Unidades de Conservação. In: BRASIL, Ministério do Meio Ambiente. Dez Anos do Sistema Nacional de Unidades de Conservação da Natureza - Lições do passado, Realizações Presentes e Perspectivas para o futuro. Brasília, 2011.

RIO DE JANEIRO. Parques da Copa 2014 : Parques Estaduais do Rio de Janeiro. Disponível em: < http://www.rj.gov.br/c/document_library/get_file?uuid=ba285919-5b5a4de1-ba8f-02b9cd820e75\&groupId=132946 >. Acesso em: 15 set. 2012.

SINAY, L. Sistema de Gestão do Uso Público das Unidades de Conservação da Natureza. I Encontro Científico sobre Uso e Conservação de Montanhas, 2012. Rio de Janeiro: Eco Montanhas, 2012. 